\title{
Psychological Stress and Perceived School Success Among Parents of Children with Developmental Disabilities During the COVID-19 Pandemic
}

\author{
Sanyin Cheng ${ }^{1}\left[\right.$ ] $\cdot$ Yuqin Yang $^{2} \cdot$ Meng Deng $^{3}$
}

Accepted: 19 July 2021 / Published online: 28 July 2021

(c) The Author(s), under exclusive licence to Springer Science+Business Media, LLC, part of Springer Nature 2021

\begin{abstract}
This study mainly explored psychological stress caused by the COVID-19 among parents in developmental disabilities and how it was related to parents' views of school success in mainland China. The Psychological Stress Questionnaire and Views of Social and Academic Success were administered to 1919 parents of children with developmental disabilities. Results showed that parent characteristics including gender, age, educational level, family income and job nature and children characteristics (i.e., disability types) were related to psychological stress caused by the COVID-19, and that psychological stress caused by the COVID-19 significantly negatively predicted parents' views of school success. The contributions, limitations, and implications of the present research are discussed.
\end{abstract}

Keywords Psychological stress · Developmental disabilities $\cdot$ Views of school success

\section{What this Paper Adds?}

This paper explores psychological stress caused by the COVID-19 among parents in developmental disabilities and how it was related to parents' views of school success in mainland China. It shows that parent and children characteristics are related to psychological stress caused by the COVID-19, and that psychological stress caused by the COVID-19 significantly negatively predicts parents' views of school success. Furthermore, it explores parental stress in developmental disabilities under the COVID-19, which expands the research domain of parental stress. Results pertaining to the psychometric properties of the two inventories have enriched the data banks for the Psychological Stress Questionnaire and Views of School Success. This paper

Sanyin Cheng

ccnu1314@163.com

1 Department of Philosophy and Social Development, Shandong University, Jinan, China

2 Hubei Research Center for Educational Informationization, Faculty of Artificial Intelligence in Education, Central China Normal University, Wuhan, China

3 Faculty of Education, Beijing Normal University, Beijing, China discusses it limitations in relation to participants as well as the adopted inventories and implications for future pandemics on closely related areas such as mental health, education and surrounding families of children with developmental disabilities.

\section{Introduction}

COVID-19 has become pandemic and many government decrees have declared restrictive measures in order to prevent its wider spread. For parents and children, staying at home is one of these measures (Narzisi, 2020). This situation may give rise to great stress for parents. For instance, they may worry about the economic and physical health of their family; they may be concerned about their children's social isolation from peers and teachers; they may be preoccupied with the management, duration, and outcomes of homeschooling (Fontanesi et al., 2020). For parents in developmental disabilities, they need to deal with more increasing demands, including their children's chronic emotional or behavioral difficulties, or other health challenges (Coyne et al., 2020).

A number of studies have explored psychological stress during previous pandemics and from the beginning of the COVID-19 outbreak, most studies focus on the general 
population, few on parents (Brooks et al., 2020; Spinelli et al., 2020), let alone parents in developmental disabilities. The present research aims to explore psychological stress caused by the COVID-19 among parents in developmental disabilities and its correlation with parents' views of school success in mainland China, for the following three reasons. Parents' views of school success herein means what parents believe that the child is doing well in school.

First, in January 2020, 2019 novel coronavirus was declared as the first-level public health emergency response in mainland China. On January 30, 2020, it was declared as Public Health Emergency of International Concern (PHEIC) by the World Health Organization. During the outbreak period, negative emotions such as tension and anxiety began to appear and iterate across mainland China (Lima et al., 2020), letting the whole society into psychological crisis. Within this context, Chinese people bear a huge work pressure and psychological pressure, which may have a certain impact on their emotional state, and make them engender psychological stress. Therefore, it deserves to investigate psychological stress caused by the COVID-19 in the context of mainland China.

Second, from 2012 to 2019 , the number of students in need of special services enrolled in ordinary schools increased from 199,800 to 394,300, with an increase of 97.3\% (Ministry of Education of the People's Republic of China). A preliminary study conducted in China reported the presence of psychological difficulties in children during the COVID-19 pandemic, with fear, clinging, inattention, and irritability as the most severe symptoms for younger children (Jiao et al., 2020). However, what specific COVID-19 related risk factors may lead to children's negative outcomes and how COVID-19 lockdown and parents' wellbeing interact on children's adjustment, have not been investigated yet. Wang et al. (2020) proposed that family processes, protective factors, and risk factors in the home environment should be more deeply understood in order to improve children's wellbeing in these difficult times. Hence, the present research chose to explore one risk factor-parental stress in developmental disabilities.

Third, although studies have investigated the influential factors of parental stress during the COVID-19 (e.g., Wu et al., 2020), few are related to the impact of parental stress during the COVID-19. Parental stress not only affects children's development across different domains (Fontanesi et al., 2020), but also influences parenting (Brown et al., 2020). Given that parental stress imposes an impact on children's developmental outcomes through parenting (Frontini et al., 2016), it is worthwhile examining how parental stress influences parenting (i.e., parents' views of school success). It should be noted that there are many dimensions of parenting. Since parents' views of school success plays an important role in child development, and it has been rarely investigated, this study focuses on parents' views of school success.

\section{Parental Stress in Developmental Disabilities and Its Influence on Parenting}

There are three lines of studies concerning parental stress in developmental disabilities. The first line relates to the level of parental stress. The second line aims to reduce parental stress through either exploring the influential factors or conducting interventions. The third line focuses on the impact of parental stress.

The first line is concerned with the level of parental stress. Hintermair (2000) found that parents of children who are hearing impaired with additional disabilities reported significantly high levels of parental stress than those of children who are without additional disabilities. Jijon and Leonard (2020) identified that two thirds of parents of children with developmental coordination disorders reported clinicallysignificant levels of stress. To be specific, the mean score (101.10; $\mathrm{SD}=24.09)$ was above the clinical cut-off of 90 suggested by Abidin (1995). This difference was significant, $\mathrm{t}(173)=6.08, \mathrm{p}<.001$.

The second line indicated that influential factors of parental stress consisted of children's characteristics, parents' characteristics and environmental factors. For instance, parental stress differed by children's disability types (Gupta, 2007) and the severity of children's disability (Rivard et al., 2014). Najmi et al. (2018) found that mother's psychological characteristics such as marital satisfaction, psychological problems and coping styles are significant determinants of parenting stress among mothers of children with different disabilities. Patton et al. (2018) indicated that high social support was related to lower parent-related stress. Hsiao et al. (2017) found that family-teacher partnerships had an indirect effect on parental stress through family quality of life among parents of children with autism.

The third line showed that parental stress in developmental disabilities influenced children's developmental outcomes across different domains (e.g., Dirks et al., 2016; Meppelder et al., 2015) and parenting. Regarding the impact of parental stress on parenting, Woolfson and Grant (2006) identified that higher levels of parental stress in developmental disabilities were related to authoritative parenting approaches. Shawler and Sullivan (2017) identified that use of harsh and punitive parental discipline strategies mediated the relationships between parent stress and child disruptive behavior problems among parents of children with autism. Hutchison et al. (2016) suggested that increased parenting stress was associated with greater use of authoritarian and permissive parenting styles among parents of children with autism or 
ADHD. Hutchison et al. (2016) findings were further confirmed in Ueda et al. (2020).

To sum up, previous studies have showed that a number of variables are related to parental stress in developmental disabilities. However, most studies focus on its influential factors, less on its impact, especially its impact on parenting. Furthermore, most studies are concerned with parents for children with one specific type of disability such as autism, few on those of children with different types of disabilities.

Given that parenting mediates the impact of parental stress (Frontini et al., 2016), it is valuable to explore how parental stress is related to parenting (i.e., parents' views of school success).

\section{Studies Regarding Chinese Parents' Views of Education}

Chinese scholars have reached an agreement on parents' views of education. For instance, Chen and He (1994) as well as Yu and Xin (1995) believed that parents' views of education mainly include the concept of talents, parent-child, children and child education.

Studies regarding Chinese parents' views of education mainly aim to explore the present situation of parents' views of education and its influential factors. For example, Li and Guan (1995) identified that parents' concept of talent emphasizing intelligence and high expectations; parents' concept of education focusing on morality; and parents concept of children recognizing the self-control of children and requiring children to be dependent on adults.

Li et al. (2002) also attempt to improve parents' views of education through interventions including pertinent educational and psychology theories learning, the parent example setting, situation activities for parent-child interaction, regular assessment and timely guidance, group experiments and case studies. Results showed that, after the intervention: (1) Parents' views of education in the experimental class are significantly better; (2) Students' evaluation of their parents' educational attitudes in the experimental class was higher than that in the control class. The parent-child relationship of the experimental class family has been significantly improved; (3) The problem behavior of students in the experimental class dropped significantly in comparison those in the control class, while their academic performance was greatly improved compared to the control class.

However, these studies were outdated and only sampled in one area of the country. In addition, these studies mainly explored how parents' demographic characteristics are correlated with parents' views of education, few on parents' individual difference variables. Yu and Xin (1995) argued that parents' views of education derive from the interaction between self-construction and culture, which emphasizes the importance of parents' individual difference variables for parents' views of education. Consequently, it is worthy to explore how parents' individual difference variable (i.e., psychological stress caused by the COVID-19) is related to parents' views of education.

\section{The Present Research}

The present research aims to explore psychological stress caused by the COVID-19 among parents in developmental disabilities and how it is related to parents' views of school success in mainland China. Considering the importance of demographic variables such as age, gender, and educational level to parents' views of education (e.g., Li, 1999), these factors need to be considered when analyzing the relationships of parents' psychological stress caused by the COVID19 to their views of school success.

Two hypotheses were made. The first was that characteristics of children such as disability types and the severity of children's disability and those of parents would be significantly related to parents' psychological stress caused by the COVID-19. The second was that parents' psychological stress caused by the COVID-19 would be negatively related to their views of school success. The hypothesis' empirical foundations reveal that characteristics of children and parents significantly predicted parental stress (e.g., Gupta, 2007; Najmi et al., 2018), and that parental stress would be related to negative parenting (e.g., Shawler \& Sullivan, 2017; Ueda et al., 2020; Woolfson \& Grant, 2006).

\section{Participants}

Parents in the present research were drawn across the whole country. The inclusion criteria for parents were as follows: (1) their children has one type of disability; (2) their children were educated in special school; (3) their children live at home with them. The second inclusion criteria means that parents of children who were in special school may perceive school success differently, because in China, most special schools do not require their students to be educated further. In addition, this study needs to be further conducted among parents of children who are educated in mainstream schools. The final research cohort consisted of 1919 parents from all the 31 provinces in mainland China. See Table 1 for detailed demographic information of parents and specific information to their children with developmental disabilities.

\section{Measures}

A demographic sheet and the two inventories aforementioned were used to collect data. The demographic sheet was used for collecting parents' personal information (e.g., 
Table 1 The distribution of parents by demographic data (total responses: 1919)

\begin{tabular}{ll}
\hline & N/Percentage \\
\hline Gender & \\
Male & $557(29 \%)$ \\
Female & $1362(71.1 \%)$ \\
Age & \\
$21-30$ & $76(4 \%)$ \\
$31-40$ & $820(42.7 \%)$ \\
$41-50$ & $841(43.8 \%)$ \\
$51-60$ and above & $182(9.5 \%)$ \\
Educational level & \\
Below high school & $813(42.4 \%)$ \\
High school or technical secondary school & $389(20.3 \%)$ \\
Junior college & $314(16.4 \%)$ \\
Above undergraduate & $403(21 \%)$ \\
Family monthly income & \\
Below 5000 RMB & $1075(56 \%)$ \\
5000-10,000 RMB & $527(27.5 \%)$ \\
10,000-20,000 RMB & $199(10.4 \%)$ \\
Above 20,000 RMB & $118(6.1 \%)$ \\
Job nature & \\
Unemployed & $315(16.4 \%)$ \\
Part-time job & $292(15.2 \%)$ \\
Full-time job & $718(37.4 \%)$ \\
Full-time homework & $594(31 \%)$ \\
Vhild's disability type & \\
Hearing impairment & $31(1.6 \%)$ \\
Speech impairment & $199(10.4 \%)$ \\
Intellectual disability & $92(4.8 \%)$ \\
Autism & $832(43.46 \%)$ \\
Physical disability & $473(24.6 \%)$ \\
Multiple disabilities & \\
\hline
\end{tabular}

gender and educational level) and information specific to their children with developmental disabilities (i.e., disability types). Two inventories are detailed below.

\section{The Psychological Stress Questionnaire (Wang et al., 2020)}

Psychological Stress Questionnaire is a newly-developed and 5-likert Chinese scale. It includes 9 items. Wang et al. (2020) identified three dimensions: (a) risk awareness, which reflects the self-evaluation of the risk stoicism of the subject's environment; (b) physical and mental response, which reveals the stress response to the subject's current environment; (c) optimistic hope, which mirrors how much the subjects were confident in defeating the epidemic and the optimism of the current outbreak. Sample item includes "Are you concerned about being infected during your work".
This questionnaire was originally developed to investigate medical staff's psychological stress caused by COVID- 19 . The range for risk awareness, physical and mental response, and optimistic hope are respectively $0-15,0-20,0-10$.

\section{Views of Social and Academic Success (Ryan et al., 2010)}

Views of social and academic success is a 5-likert and selfreport inventory, ranging from 1 (Not at all important) to 5 (Extremely important). It was developed in English, translated into Chinese, and then back-translated into English. It includes two subscales: academic success and social success. Academic success includes ten items, assessing how important it was that their children be academically successful (e.g., get good grades, learn math, and get the right answers). Social success includes eight items, assessing how important it was to parents that their children be socially successful (e.g., show respect for teachers, follow directions, and play well with others). This inventory has demonstrated to be reliable and valid in the study conducted by Ryan et al. (2010).

\section{Procedures}

The online questionnaire was first introduced to the school principal of special schools across the 31 provinces by the third author, one professor and has very good relationships with all these principal. These principal distribute and introduce the questionnaire to parents. They gave strong encouragement to parents for children in their school.

All research participants were first required to complete and return informed consent forms online, which highlighted that their participation was voluntary, and that all information obtained would be kept strictly confidential and be used only for research purposes. The demographic sheet and three inventories were administered online. The demographic sheet was anonymous. The procedure took around $20 \mathrm{~min}$. In appreciation of their participation, parents were given random red packet with the odd of one in third as reward. They were aware ahead of time that they would be given reinforcement for participation.

\section{Data Analysis}

The reliability values for the two inventories aforementioned were first estimated using Cronbach's alpha coefficients, after which confirmatory factor analysis (CFA) was conducted to test their validity. Furthermore, descriptive statistics were calculated.

In addition, a series of MANOVAs were conducted to explore how demographic variables are related to views of social and academic success.

Finally, multiple regressions were conducted to predict views of social and academic success from parents' 
psychological stress caused by the COVID-19, with relevant demographic factors being controlled for; specifically, multiple regressions were performed separately for each of the two views of social and academic success scales, with parents' psychological stress caused by the COVID-19 serving

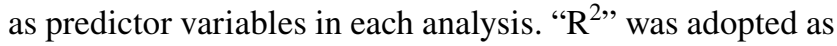
the indicator for effect sizes, with small, medium, and large effect sizes being represented by the values of $0.01,0.09$, and 0.25, respectively (Cohen, 1992).

\section{Results}

\section{Reliability and Validity of the Two Investigated Inventories}

The internal consistency reliability of the Psychological Stress Questionnaire is .62. This is consistent with that of Wang et al. (2020). The reliability values for the two subscales regarding Views of Social and Academic Success are: academic success $=.90$; social success $=.90$. This is consistent with that of Ryan et al. (2010).

Results of CFA indicated that three-factor psychological stress was unacceptable for parents of children with developmental disabilities. The model fit indices obtained through CFA for the one-factor psychological stress model were: $\chi^{2} / \mathrm{df}=3.2, \mathrm{RMSEA}=.03, \mathrm{CFI}=.99, \mathrm{GFI}=.99$. Per Byrne (1989), Bentler and Bonnett (1980), Browne and Cudeck (1993), and Hu and Bentler (1999), acceptable values for these fit indices are: $\chi^{2} / \mathrm{df}(<1.50$ to $<.5 .00)$; RMSEA $(<.06$ to $<.10)$, GFI and CFI (around .90). Thus, the onefactor psychological stress model was deemed acceptable for parents of children with developmental disabilities. The standardized parameter estimates are presented in Table 2. In order to be consistent with the original study and make results more comparable, the present research input three dimensions into the following regression.

The model fit indices obtained through CFA for the two-factor views of social and academic success model were: $\chi^{2} / \mathrm{df}=4.8$, RMSEA $=.05, \mathrm{CFI}=.99$, GFI $=.98$. Per

Table 2 Standardized parameter estimates for the one-factor model of psychological stress

\begin{tabular}{ll}
\hline Item & \\
\hline Item1 & .32 \\
Item2 & .35 \\
Item3 & .59 \\
Item4 & .77 \\
Item5 & .51 \\
Item6 & .86 \\
Item7 & .51 \\
Item8 & .73 \\
Item9 & .32 \\
\hline
\end{tabular}

Byrne (1989), Bentler and Bonnett (1980), Browne and Cudeck (1993), and Hu and Bentler (1999), acceptable values for these fit indices are: $\chi^{2} / \mathrm{df}(<1.50$ to $<.5 .00)$; RMSEA (<.06 to <.10), GFI and CFI (around .90). Thus, the two-factor views of social and academic success model were deemed acceptable for parents of children with developmental disabilities. The standardized parameter estimates are presented in Table 3.

\section{Descriptive Statistics}

Descriptive analysis was conducted. Means and standard deviations concerning each scale of psychological stress and views of academic and social success measures are reported in Table 4. As indicated, parents' psychological stress level is above the average score.

Table 3 Standardized parameter estimates for the two-factor model of views of academic and social success

\begin{tabular}{lll}
\hline Item & Academic success & Social success \\
\hline Item1 & & .67 \\
Item2 & .50 & \\
Item3 & .38 & \\
Item4 & .60 & .75 \\
Item5 & & .84 \\
Item6 & & \\
Item7 & .74 & .65 \\
Item8 & & .87 \\
Item9 & & \\
Item10 & .67 & .89 \\
Item11 & .74 & .75 \\
Item12 & & .81 \\
Item13 & & \\
Item14 & & \\
Item15 & .82 & \\
Item16 & .71 & \\
Item17 & .62 & \\
Item18 & .58 & \\
\hline
\end{tabular}

Table 4 Means (M) and standard deviations (SD) of Psychological Stress Questionnaire and Views of Academic and Social Success

\begin{tabular}{lrl}
\hline Scale & \multicolumn{1}{c}{ M } & SD \\
\hline Risk awareness & 8.45 & 1.84 \\
Physical and mental response & 12.40 & 2.46 \\
Optimistic hope & 3.94 & 1.46 \\
Academic success & 38.09 & 6.44 \\
Social success & 32.45 & 5.01 \\
\hline
\end{tabular}




\section{The Relationships of Parent and Children Characteristics to Parents' Psychological Stress Caused by the COVID-19}

Results of MANOVAS showed that parent characteristics significantly affect their psychological stress caused by the COVID-19. To be specific, using Pillai's trace, there was a significant effect of gender on parents' psychological stress caused by the COVID-19 with male higher than female, $\mathrm{V}=0.01, \mathrm{~F}(3,1915)=3.61, \mathrm{p}=0.013$. Using Pillai's trace, there was a significant effect of age on parents' psychological stress caused by the COVID-19 with the older higher than the younger, $\mathrm{V}=0.03, \mathrm{~F}(12,5742)=4.25, \mathrm{p}=0.000$. Using Pillai's trace, there was a significant effect of educational level on parents' psychological stress caused by the COVID19 with the higher having the higher stress level, $\mathrm{V}=0.04$, $\mathrm{F}(9,5745)=8.13, \mathrm{p}=0.000$. Using Pillai's trace, there was a significant effect of family income on parents' psychological stress caused by the COVID-19 with the higher having the higher stress level, $\mathrm{V}=0.02, \mathrm{~F}(9,5745)=4.82$, $p=0.000$. Using Pillai's trace, there was a significant effect of job nature on parents' psychological stress caused by the COVID-19 (those with full-time job had the highest level of stress), $\mathrm{V}=0.03, \mathrm{~F}(12,5742)=3.12, \mathrm{p}=0.001$.

Results of MANOVAS showed that children characteristics significantly affect parents' psychological stress caused by the COVID-19. To be specific, using Pillai's trace, there was a significant effect of children's disability types on parents' psychological stress caused by the COVID-19 with the autism having the highest stress level, $\mathrm{V}=0.02, \mathrm{~F}(18$, $5736)=2.62, \mathrm{p}=0.000$.

\section{Predicting Views of Children's School Success from Parents' Psychological Stress Caused by the COVID-19}

Hierarchical multiple regression analyses were used to test the hypothesis, which predicted parents' psychological stress caused by the COVID-19 would be negatively related to their views of children's school success. Results showed that, as predicted, one dimension of parents' psychological stress caused by the COVID-19 significantly negatively predicted their views of children's school success beyond demographic variables including age, educational level, family income, job nature, and children's disability type. Please see Table 5 for details.

\section{Discussion}

The principal objective of this study was to investigate explore psychological stress caused by the COVID19 among parents in developmental disabilities and it
Table 5 Predicting parents' view of children's school success from their psychological stress caused by the COVID-19

\begin{tabular}{lll}
\hline & Academic success & Social success \\
\hline $\mathrm{R}_{2}$ & .02 & .03 \\
$\beta_{\mathrm{oh}}$ & $-.14^{* * *}$ & $-.16^{* * *}$ \\
$\mathrm{~F}$ & 11.94 & 6.59 \\
$\mathrm{df}$ & $(9,1909)$ & $(9,1909)$ \\
\hline
\end{tabular}

correlation with parents' views of school success in mainland China. To that end, a preliminary step was taken to validate the Chinese version of the Psychological Stress Questionnaire and views of social and academic success among parents for children with developmental disabilities in mainland China.

Results indicated that parent characteristics including gender, age, educational level, family income and job nature and children characteristics (i.e., disability types) were related to psychological stress caused by the COVID19 , and that psychological stress caused by the COVID-19 significantly negatively predicted parents' views of school success, supporting this study's two hypotheses. It should be noted that regression analysis yielded statistically significant results for only one dimension of parents' psychological stress. While seemingly limited, these results are nonetheless statistically significant and are likely to be meaningful data, rather than statistical anomalies, for three reasons.

First, there is no construct similarity between psychological stress caused by the COVID-19 and parents' views of school success. The former includes three dimensions: (1) risk awareness, which reflects the self-evaluation of the risk stoicism of the subject's environment; (2) physical and mental response, which reveals the stress response to the subject's current environment; and (3) optimistic hope, which mirrors how much the subjects were confident in defeating the epidemic and the optimism of the current outbreak. The latter consists of two dimensions: (1) academic success assesses how important it was that their children be academically successful; and (2) social success assesses how important it was to parents that their children be socially successful.

Second, parents with higher levels of psychological stress caused by the COVID-19 scored lower on their views of school success. During the COVID-19, parents including those for children with developmental disabilities across mainland China were forced to do more homeschooling. In addition, parents for children with developmental disabilities were also required to do home interventions. All these challenges may exacerbate behavior and emotional problems of children with developmental disabilities, which may frustrate their parents and make them devaluate children's school success. Therefore, it is reasonable to find a negative relationship between parents' psychological stress caused by the COVID-19 and their views of school success. However, 
these interpretations do not indicate a causal relationship between the two constructs. It is equally likely that during the COVID-19, parents' lower scores on view of school success would lead them to have higher levels of psychological stress caused by the COVID-19.

Third, the findings of the present research are also in line with those of previous studies, in which characteristics of children and parents significantly predicted parental stress (e.g., Gupta, 2007; Najmi et al., 2018), and that parental stress would be related to negative parenting (e.g., Shawler \& Sullivan, 2017; Ueda et al., 2020; Woolfson \& Grant, 2006).

The above explanations are only post-hoc speculations. If future research yields similar findings, researchers are urged to explore further by conducting follow-up interviews.

\section{Significance, Limitations, and Implications}

This study makes three significant contributions to the existing research. First, it pioneers in investigating the impact of COVID-19 on parenting for children with developmental disabilities in the context of mainland China, which has a large number of children with developmental disabilities and has been greatly affected by the COVID-19. Second, it explored parental stress in developmental disabilities under the COVID-19, which greatly expand the research domain of parental stress. Third, results pertaining to the psychometric properties of the two inventories have enriched the data banks for the Psychological Stress Questionnaire and Views of School Success. It is worth noting this is the first study to have validated Views of School Success among parents of children with developmental disabilities in the Chinese context, through confirmatory factor analysis.

However, the present research has four major limitations. First, this is a correlational study; a longitudinal exploration of the effects of quarantine on parents in developmental disabilities would help in better understanding the phenomenon. Second, we have collected data from parents' self-report; although this data collection method is widely used it may be less objective than behavioral measures.

Third, the male/female distribution of parents was uneven. Fourth, for various reasons, information was not gathered regarding the severity of children's disability, which may have influenced the results of the present research. These limitations indicate the findings reported herein should be considered preliminary, rather than definitive. However, since there are good reasons to believe that the present data are meaningful, some implications may be proposed for future pandemics on closely related areas such as mental health, education and surrounding families of children with developmental disabilities.
First, given that parents' psychological stress caused by COVID-19 is above the average level and parents' mental health greatly affects children's developmental outcomes and parenting, governments should put great emphasis on parents' mental health during the COVID-19 or future pandemics and take immediate and effective measures to enhance it. For instance, governments may provide guidelines on how to reach existing public and private health and social welfare services; they may also quickly develop mental health interventions for parents to address worries, distress, dysfunctional coping strategies, and negative parental behaviors.

The second implication concerns education for children with developmental disabilities during the COVID-19 or future pandemics. Since homeschooling, especially home therapy is one major detrimental factor for parental stress (Fontanesi et al., 2020; Narzisi, 2020), public health and special schools should provide parents with knowledge about, for instance, how children with developmental disabilities at different ages express distress and the importance of sharing and talking about fears and negative emotions (Dalton et al., 2020). Through this way, even under stress, parents may still be able to educate their children in appropriate ways (Belsky, 1984).

Third, as parents scored higher on psychological stress caused by the COVID-19 scored lower on their views of school success, efforts can be made to improve parenting views of school success through reducing their psychological stress caused by the COVID-19 or future pandemics. For instance, university/school therapists may provide a weekly online consultation. A special teacher may be arranged to mainly contact with parents online or by phone. Parents may also share video game and/or internet sessions of their children with other parents.

Acknowledgments All the thanks will be given to all the participants. This study has no funding.

Author Contributions SC is involved in the whole process of the manuscript. She design the study, conduct the study, and write the paper. YY helps to collect and analyze the data. MD provides ideas on how to revise the paper before and during the submission and revision process.

\section{Declarations}

Conflict of interest The authors declare that they have no conflict of interest.

\section{References}

Abidin, R. R. (1995). Parenting stress index (3rd ed.). Odessa, FL: Psychological Assessment Resources.

Belsky, J. (1984). The determinants of parenting: A process model. Child Development, 55(1), 83-96. 
Bentler, P. M., \& Bonett, D. G. (1980). Significance tests and goodness of fit in the analysis of covariance structures. Psychological Bulletin, 88, 588-606.

Brooks, S. K., Webster, R. K., Smith, L. E., Woodland, L., Wessely, S., Greenberg, N., \& Rubin, G. J. (2020). The psychological impact of quarantine and how to reduce it: Rapid review of the evidence. The Lancet, 395, 912-920.

Brown, S. M., Doom, J. R., Lechuga-Peña, S., Watamura, S. E., \& Koppels, T. (2020). Stress and parenting during the global COVID-19 pandemic. Child Abuse \& Neglect, 110, 104699.

Browne, M. W., \& Cudeck, R. (1993). Alternative ways of assessing model fit. In K. A. Bollen \& J. S. Long (Eds.), Testing structural equation models (pp. 136-162). Newbury Park, CA: Sage.

Byrne, B. M. (1989). A primer of LISREL. New York, NY: Springer.

Chen, \& He. (1994). Parents' views of education-A new concept worthy of attention. Family Education (Kindergarten Edition), 1, 47.

Cohen, J. (1992). A power primer. Psychological Bulletin, 112(1), 155.

Coyne, L. W., Gould, E. R., Grimaldi, M., Wilson, K. G., Baffuto, G., \& Biglan, A. (2020). First things first: Parent psychological flexibility and self-compassion during COVID-19. Behavior Analysis in Practice. https://doi.org/10.1007/s40617-020-00435-w

Dalton, L., Rapa, E., \& Stein, A. (2020). Protecting the psychological health of children through effective communication about COVID19. The Lancet Child \& Adolescent Health, 4(5), 346-347.

Dirks, E., Uilenburg, N., \& Rieffe, C. (2016). Parental stress among parents of toddlers with moderate hearing loss. Research in Developmental Disabilities, 55, 27-36.

Fontanesi, L., Marchetti, D., Mazza, C., Di Giandomenico, S., Roma, P., \& Verrocchio, M. C. (2020). The effect of the COVID-19 lockdown on parents: A call to adopt urgent measures. Psychological Trauma: Theory, Research, Practice, and Policy, 12(S1), S79-S81.

Frontini, R., Moreira, H., \& Canavarro, M. C. (2016). Parenting stress and quality of life in pediatric obesity: The mediating role of parenting styles. Journal of Child and Family Studies, 25(3), $1011-1023$.

Gupta, V. B. (2007). Comparison of parenting stress in different developmental disabilities. Journal of Developmental and Physical Disabilities, 19(4), 417-425.

Hintermair, M. (2000). Children who are hearing impaired with additional disabilities and related aspects of parental stress. Exceptional Children, 66(3), 327-332.

Hsiao, Y. J., Higgins, K., Pierce, T., Whitby, P. J. S., \& Tandy, R. D. (2017). Parental stress, family quality of life, and family-teacher partnerships: Families of children with autism spectrum disorder. Research in Developmental Disabilities, 70, 152.

Hu, L.-T., \& Bentler, P. M. (1999). Cut-off criteria for fit indexes in covariance structure analysis: Conventional criteria versus new alternatives. Structural Equation Modeling, 6, 1-55.

Hutchison, L., Feder, M., Abar, B., \& Winsler, A. (2016). Relations between parenting stress, parenting style, and child executive functioning for children with ADHD or autism. Journal of Child and Family Studies, 25(12), 3644-3656.

Jiao, W. Y., Wang, L. N., Liu, J., Fang, S. F., Jiao, F. Y., PettoelloMantovani, M., \& Somekh, E. (2020). Behavioral and emotional disorders in children during the COVID-19 epidemic. The Journal of Pediatrics, 221, 264.

Jijon, A. M., \& Leonard, H. C. (2020). Parenting stress in parents of children with developmental coordination disorder. Research in Developmental Disabilities, 104, 103695.

Li. (1999). A survey report on the status quo of parents' views of education in primary and secondary schools and kindergartens in Shanghai. Shanghai Educational Research, 2, 3-5.

Li, \& Guan. (1995). A survey on views of education among parents of preschool children in Tianjin. Preschool Education Research, $3,18-20$.
Li, Wang, F. S., \& Wang, Y. (2002). Experimental exploration to promote the transformation of parents' views of education. Educational Research, 4, 67-73.

Lima, C. K. T., de Medeiros Carvalho, P. M., Lima, I. D. A. S., de Oliveira Nunes, J. V. A., Saraiva, J. S., de Souza, R. I., da Silva, C. G., \& Neto, M. L. R. (2020). The emotional impact of Coronavirus 2019-nCoV (new Coronavirus disease). Psychiatry Research, $287,112915$.

Meppelder, M., Hodes, M., Kef, S., \& Schuengel, C. (2015). Parenting stress and child behaviour problems among parents with intellectual disabilities: The buffering role of resources. Journal of Intellectual Disability Research, 59(7), 664-677.

Najmi, B., Heidari, Z., Feizi, A., Hovsepian, S., Momeni, F., \& Azhar, S. M. M. (2018). Do psychological characteristics of mothers predict parenting stress? A cross-sectional study among mothers of children with different disabilities. Archives of Psychiatric Nursing, 32(3), 396-402.

Narzisi, A. (2020). Handle the autism spectrum condition during Coronavirus (COVID-19) stay at home period: Ten tips for helping parents and caregivers of young children. Brain Sciences, 10, 1-4.

Patton, K. A., Ware, R., McPherson, L., Emerson, E., \& Lennox, N. (2018). Parent-related stress of male and female carers of adolescents with intellectual disabilities and carers of children within the general population: A cross-sectional comparison. Journal of Applied Research in Intellectual Disabilities, 31(1), 51-61.

Rivard, M., Terroux, A., Parent-Boursier, C., \& Mercier, C. (2014). Determinants of stress in parents of children with autism spectrum disorders. Journal of Autism and Developmental Disorders, 44(7), 1609-1620.

Ryan, C. S., Casas, J. F., Kelly-Vance, L., Ryalls, B. O., \& Nero, C. (2010). Parent involvement and views of school success: The role of parents' Latino and White American cultural orientations. Psychology in the Schools, 47(4), 391-405.

Shawler, P. M., \& Sullivan, M. A. (2017). Parental stress, discipline strategies, and child behavior problems in families with young children with autism spectrum disorders. Focus on Autism and Other Developmental Disabilities, 32(2), 142-151.

Spinelli, M., Lionetti, F., Pastore, M., \& Fasolo, M. (2020). Parents' stress and children's psychological problems in families facing the COVID-19 outbreak in Italy. Frontiers in Psychology, 11, 1713.

Ueda, M. M., Ding, Y., Blumberg, F., Zhang, C., Yu, Q., \& Lantier, K. (2020). Maternal parenting style in relation to parenting stress and behavioral outcomes in Japanese children with and without autism. Journal of Developmental and Physical Disabilities. https://doi.org/10.1007/s10882-020-09727-Z

Wang, J., Cheng, Y., Zhou, Z., Jiang, A., Guo, J., Chen, Z., \& Wan, Q. (2020). Psycological status of Wuhan medical staff in fighting against COVID-19. Medical Journal of Wuhan University, 41(4), 547-550.

Woolfson, L., \& Grant, E. (2006). Authoritative parenting and parental stress in parents of pre-school and older children with developmental disabilities. Child: Care, Health and Development, 32(2), $177-184$.

Wu, M., Xu, W., Yao, Y., Zhang, L., Guo, L., Fan, J., \& Chen, J. (2020). Mental health status of students' parents during COVID19 pandemic and its influence factors. General Psychiatry, 33(4), e 100250

Yu, \& Xin. (1995). Research on parents' views of education from the perspective of social cognition. Journal of East China Normal University (Educational Science Edition), 3, 87-93.

Publisher's Note Springer Nature remains neutral with regard to jurisdictional claims in published maps and institutional affiliations. 